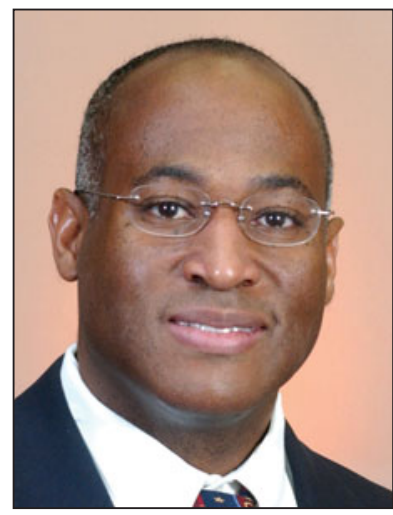

Peter F. Green named inaugural editor-in-chief of MRS Communications

$\mathbf{T}$ he Materials Research Society (MRS) has named Peter F. Green as editor-in-chief of its newest publication, MRS Communications. Green is the Vincent T. and Gloria M. Gorguze Professor of Engineering and Chair of the Materials Science and Engineering Department at the University of Michigan. $\mathrm{He}$ is also the Director of the University of Michigan's DOE Energy Frontier Research Center: Center for Solar and Thermal Energy Conversion in Complex Materials. Green has a long history of involvement with MRS, including as the Society's president in 2006.

MRS Communications was launched by MRS and Cambridge University Press in 2011 to serve the international materials research community. It is a full-color, online-only publication, with articles appearing immediately on Cambridge Journals Online (CJO), offering authors an exceptionally rapid review and publication process.

"The goal is for MRS Communications to become, within a few years, the materials journal where researchers send their very best cutting-edge research," said Green. "The metrics of success would include rapid publication rates, excellent refereeing, and a high impact factor. It should be a journal that people interested in materials research would look forward to reading when every new issue is published."

When asked how he plans to attract researchers to submit their top-notch work for publication, he said he was making one fundamental assumption that "MRS members will send their best work for publication to MRS Cоттиnications. However, the first few issues will be critical; we need to publish very high impact and exciting papers in these early issues. If the readers and authors agree, then we will be on the way to building a very strong journal."

Responding to a question about his motivation for accepting the position, Green said, "Many of us in the Society [MRS] believe that the time is right for such a journal. If I did not believe this, I would not have accepted this editorship!" He added, "The primary part of my [professional] volunteer activities will now be focused on MRS Communications."

Asked about "Prospectives," one of the unique features of MRS Communications, Green said, "I will be discussing this - and other types of articles that would be of great interest to readers - in more detail with the principal editors and editorial board. Prospectives will be brief reviews of emerging cutting-edge areas written by outstanding researchers. They would be different from review articles that generally focus on established areas."

MRS Communications can be accessed at www.mrs.org/mrc.

\title{
IUMRS-ICYRAM 2012 conference of young researchers organized by MRS-Singapore www.mrs.org.sg/icyram2012
}

T he International Union of Materials Research Societies (IUMRS) is launching a new Global Materials Network (GMN). At an inaugural meeting of GMN, IUMRS will present a new conference, the International Conference of Young Researchers on Advanced Materials (ICYRAM), designed specifically with young researchers in mind. The conference, organized by MRS-Singapore, will be held on July 1-6, 2012 in Singapore.

The mission of ICYRAM is to pro- vide a platform for materials researchers under the age of 40 to present technical findings of their research, to network within the international community of other young researchers, and to increase the breadth of their general materialsbased knowledge. Participants will also have opportunities to seek the insight and advice of successful senior researchers through plenary sessions and instructive seminars. Panel sessions will be held in both small and large settings, for focused and general discussions. The aim is to create an environment for interaction and the exchange of perspectives across a broad range of materials-related topics.

The technical program will cover biomaterials and health care, energy and the environment, electronic materials, optical materials, magnetic and spintronic materials, and carbon-based materials.

To receive updates or participate in the development of ICYRAM, visit www.mrs.org.sg/icyram 2012. 